\title{
Auto-borradores: la antropología y la cultura difuminándose mutuamente
}

\author{
Auto-Drafts: Or Anthropology Blurring Culture, \\ and Vice Versa
}

\author{
Alberto Corsín Jiménez \\ CSIC \\ alberto.corsin-jimenez@cchs.csic.es
}

\section{RESUMEN}

¿Qué clase de relato es el relato etnográfico? ¿Qué tipo de relaciones sociales y relaciones empíricas se entremezclan y confunden en él? El artículo repasa brevemente la historia de la primera ciencia experimental en el siglo XVII, donde nació el concepto de 'relación' como a un tiempo descriptor sociológico (para hablar de 'relaciones sociales') y descriptor analítico (para dar razón de fenómenos empíricos). Esta doble capacidad de la relación para ver y dejarse ver simultáneamente ha jugado un papel central en la historia de la etnografía. Hoy vemos aparecer, sin embargo, contextos y espacios de experimentación en los que los momentos descriptivos y analítico quedan difuminados, ensayos por una 'cultura libre' y una 'cultura abierta' donde lo descriptivo y lo analítico se mantienen deliberadamente en suspenso, en estado 'borrador'. ¿Qué clase de relato y de relación es un borrador, y qué género etnográfico inaugura?

Palabras clave: Borradores; Prototipos; Ciencia experimental; Etnografía; Cultura libre; Cultura abierta.

\section{SUMMARY}

What kind of account is an ethnographic account? How does ethnography provide for the intermingling of social and empirical relations? This article provides a brief overview of the history of experimental science in the seventeenth century, where the concept of 'relation' was first coined both as a sociological descriptor (in 'social relations' parlance) and an analytical descriptor (to account for empirical phenomena). This dual capacity of relations to both 'see' and let themselves 'be seen' has played a fundamental role in the history of ethnography. Today, however, we are witnessing the rise of a variety of spaces of experimentation, in particular in contexts of so-called 'free culture' and 'open culture' practices, where the descriptive and the analytic are deliberately 
held in suspension and are said to work as 'drafts'. What type of account and relation is a draft? And what kind of ethnographic genre might it inaugurate?

Key words: Drafts; Prototypes; Experimental Science; Ethnography; Free Culture; Open Culture.

Quiero empezar con una breve viñeta, bien conocida en historia y estudios sociales de ciencia y tecnología. Se trata del relato que Steve Shapin y Simon Schaffer hicieron sobre los experimentos con bomba de aire de Robert Boyle, experimento famoso cuya puesta en escena supuestamente inaugura la era de la ciencia experimental (Shapin y Schaffer 1985). Del experimento se pueden decir muchas cosas pero me interesa en particular la forma que asumió como cuerpo social.

En los albores de la ciencia experimental en el siglo XVII Boyle y sus colegas confrontan toda una serie de decisiones prácticas sobre la puesta en escena de esos sus primeros experimentos. No existían, claro, laboratorios como los conocemos hoy, así que sus reuniones transitan por diversos espacios: se reúnen en boticas, en atelieres de artesanía instrumental, en salones, en las habitaciones privadas que algunos de ellos disponen en los colegios de Oxford o Cambridge, y sobre todo, en sus hogares, en sus residencias particulares. Steve Shapin, que ha documentado minuciosamente los lugares de la ciencia en el XVII, lo dice claramente: "La gran mayoría de los ensayos experimentales, de sus puestas en escena y demostraciones, así como las discusiones que los acompañan, se llevaron a cabo en residencias privadas" (Shapin 1988: 378).

La organización de aquellos primeros experimentos en residencias privadas tiene no pocas consecuencias. De una parte, en la medida en que los experimentos buscaban dar cuenta de la producción de ciertos hechos empíricos (los 'matters of fact' a que se referían los experimentalistas), el estatus "privado" de sus hogares los obligó a encontrar una fórmula que garantizara el carácter "público" de las observaciones científicas que allí se producían. Para ello, Boyle se hace acompañar de 'gentlemen', aristócratas de alta alcurnia e indudable reputación, cuya sola palabra valía para dar fe sobre las observaciones que allí acontecían.

La credibilidad de estos testigos resulta, pues, fundamental para el hecho experimental. Tanto es así, que no pocos experimentalistas coinciden en señalar la 'asamblea' de testigos como elemento fundacional de esa primera ciencia experimental. Thomas Sprat, por ejemplo, cofundador y primer historiador de la Royal Society, habla sobre el rol fundamental que las 'Asambleas desempeñaban en la resolución de disputas en torno a hechos empíricos' (citado en Steven Shapin y Schaffer 1985: 58). Unos y otros coinciden en la importancia que tiene este cuerpo asambleario, esta forma social que, aunque solapa y reverbera con otras formas de asociación propias de la época (los salones de café, en particular, pero también los clubes privados y los colegios universitarios) (Shapin 1988: 393), demanda, no obstante, un ejercicio de inventiva singular. Las asambleas, insiste Sprat, ofrecen una "cura" a esa enfermedad que aflige nuestros sistemas de conocimiento', pues en ellas, 'sus integrantes dispondrán todos de los mismos privilegios; sus beneficios serán comunes; y no se dará, entre sus miembros, relación de servidumbre alguna.' (citado en Shapin 1988: 397)

Este último punto, la autonomía y soberanía del individuo que se persona en un espacio experimental para sumar su palabra al dictado de fe que la asamblea pro- 
nuncia sobre un hecho experimental, resulta, para aquellos primeros experimentalistas, una cuestión de la más alta importancia. Pues la palabra de un hombre (y recordemos que eran siempre hombres quienes participan en aquella primera cultura experimental) vale tanto como su independencia y libertad. De poco serviría la adhesión de una persona cuya palabra se sabe comprometida por lazos de dependencia o servidumbre.

Me detengo en este punto pues nos encontramos ante un momento de inflexión importante.

Hemos visto la importancia que tienen las asambleas como espacios epistémicos en los orígenes de la historia de la experimentación. Las relaciones sociales que se dan entre aquellos curiosos aristócratas - relaciones que se sostienen, recordemos, sobre ciertas concepciones de libertad e independencia de criterio - son, precisamente por la autonomía y soberanía de razón que las acompaña, relaciones epistémicas también: los experimentos son espacios de razón porque los aristócratas que se personan como testigos son personas razonables. La 'asamblea' de los primeros experimentalistas pone en juego de este modo una curiosa figura doble, un dúplex que permite a un tiempo ensamblar cierto tipo de relaciones epistémicas (un racionalismo empiricista) sobre cierto tipo de relaciones sociales (la confianza entre aristócratas).

De hecho, en sus trabajos más recientes sobre la antropología histórica del concepto de 'relación' (relation), Marilyn Strathern ha venido a sugerir que quizás las primeras expresiones de este juego doble de la 'relación' como a un tiempo figura social y figura epistémica se encuentren, no en las asambleas de los primeros experimentalistas, sino en las dinámicas más prosaicas del hogar, la familia y el parentesco. Pues es en estos ámbitos donde encontramos por vez primera a lo largo del XVII la sorprendente adaptación del término 'relación' para re-describir ciertos tipos de vínculos familiares: donde el vocablo 'relative' empieza a usarse como genérico en lugar de 'family', 'kin' o 'kindred' (Strathern 2014: 9).

Nos encontramos pues ante un escenario en el que quizás, y conviene subrayar la dimensión especulativa de este 'quizás', es el ámbito cultural del parentesco el que posibilita las formas conceptuales de vinculación social que, poco después, acogería la 'asamblea' como vector social de esa primera experimentación científica.

Me ha parecido importante detenerme en los orígenes históricos de la cultura experimental pues encontramos allí uno de los primeros momentos de articulación del hecho experimental como a un tiempo un hecho empírico y un hecho social. Muy especialmente, me interesa resaltar de esta historia la forma sociológica que asume esa articulación: de una parte, la relación, como dúplex que reobra constantemente lo empírico sobre lo social y lo social sobre lo empírico; y de otra parte, la asamblea, como espacio de testimonio y visibilidad independiente.

Recordemos, por supuesto, que la etnografía moderna se proyecta toda ella como heredera de este doble juego relacional, en tanto que el etnógrafo/a ha de transformar las relaciones sociales de las que participa en el campo en relaciones analíticas. Dicho de otro modo, si en las asambleas del siglo XVII las relaciones sociales entre aristócratas daban fe de las relaciones analíticas que surgían del experimento, en la historia moderna de la etnografía las relaciones sociales que entabla un etnógrafo/a en el campo dan fe y (supuestamente) autorizan las relaciones analíticas que posteriormente elabora en sus escritos. 
¿Pero es fiel esta descripción de la tarea etnográfica a los desafíos que enfrentamos hoy los antropólogos/as? ¿O acaso no sería justo replantearse el papel que ocupa la etnografía como 'relacionadora' de momentos empíricos y analíticos? Al fin y al cabo, para los experimentalistas del XVII, el dúplex de la relación, su capacidad para dar nombre y articular a un tiempo dinámicas sociales $y$ demostraciones epistémicas, no fue otra cosa que un hallazgo histórico-cultural. Es decir, la relación no es un operador sociológico o epistémico universal. La relación fue una suerte de 'invención cultural' del XVII, un recurso lingüístico y cultural con el que llevar a cabo tanto descripciones específicas de ciertos modos de sociabilidad (por ejemplo, relaciones de parentesco) como descripciones más abstractas y genéricas sobre formas del conocimiento (por ejemplo, relaciones analíticas derivadas de los experimentos).

Por lo mismo, quizás haya llegado el momento de preguntarnos por otro tipo de operador heurístico y conceptual que el de 'relación', uno capaz de dar cuenta de nuestro tiempo, de las formas específicas que caracterizan nuestra forma de sociabilidad, pero capaz también de dar razón de sus formas abstractas y genéricas, de las conceptualizaciones que empleamos para explicarnos a nosotros mismos. Si lo que distingue ciertas tensiones del proyecto etnográfico en este nuestro tiempo es la experimentación en sus formas de colaboración, tal y como lo han descrito Tomás Sánchez Criado y Adolfo Estalella, ¿qué clase de concepto haría las veces hoy del dúplex relacional del XVII?

No tengo una respuesta, claro, desde luego no una para el proyecto etnográfico en su conjunto. Pero me gustaría ensayar un modelo de respuesta para la etnografía que durante los últimos cinco años he venido desarrollando con Adolfo Estalella.

Una parte importante de nuestro trabajo se ha centrado en una serie de colaboraciones con diversos colectivos de 'cultura libre' en la ciudad de Madrid (ver por ejemplo Corsín Jiménez et al. 2014; Corsín Jiménez y Estalella 2016). Estos colectivos hacen una apuesta por un urbanismo ciudadano que aspira a 'liberar' ciertas dimensiones tanto políticas como materiales del espacio público. A diferencia de otros movimientos urbanos, como los movimientos por el derecho a la ciudad o la justicia medioambiental, o los movimientos de okupación y autogestión (Harvey 2012; Sánchez-Pinilla et al. 2011), podríamos decir que la cultura libre apuesta por complejizar la ontología de la ciudad. El gesto de la cultura libre no pasa en primera instancia por la reclamación o la reivindicación, de un derecho, de una identidad política, de una libertad o de un espacio. Sin descartar estas modalidades de acción, desde la cultura libre se pretende sin embargo complejizar la ciudad como objeto de información, de sociabilidad e intensidad afectiva, y de gobernanza. Para ello es necesario 'liberar' todos los relatos posibles sobre ciudad: abriendo repositorios y archivos a distintos proyectos de documentación audio-visual; compartiendo la información, multiplicándola, cruzándola con relatos alternativos y relatos comparativos; diseñando y desarrollando infraestructuras de trabajo colaborativo, presenciales y en red; organizando derivas y paseos por la ciudad, intervenciones en el espacio público, charlas y performances; dando nuevos usos a materiales residuales o abandonados, diseñando nuevos circuitos para su circulación y aprovechamiento, etc. Todo ello con licencias copyleft, que permiten la reproducción, distribución y edición de la obra o los materiales originales.

Nuestra etnografía nos ha llevado a trabajar con instituciones culturales como Medialab-Prado e Intermediae; con colectivos de arquitectura como Basurama, Zuloark 
o LagaleríadeMagdalena; con iniciativas ciudadanas como La Mesa, \#edumeet o Hacenderas; con proyectos de gestión cultural como Citykitchen. Son estos, sin duda, proyectos muy dispares, en la medida que tienen escalas y formas organizacionales distintas, además de ámbitos de actuación propios. Pero son, de algún modo, proyectos que participan también de un mismo vector de transformación cultural. Por ellos pasan, muchas veces, las mismas personas. Comparten, frecuentemente, la misma sede o residencia, o hacen de cierto modelo de ciudad, de ciertas prácticas y formas espaciales, su sede y su residencia. Desde luego, comparten un mismo vocabulario y una misma sensibilidad, y un repertorio de herramientas de trabajo e intervención en el espacio público muy parecido. Y no pocas veces usan canales de comunicación que se cruzan y mezclan y a veces incluso se confunden.

Aunque hay ciertos lugares de reunión que se han repetido a lo largo del tiempo (Medialab, Intermediae) no creo que se pueda hablar de estos como 'espacios' de trabajo propiamente dichos. Más que 'espacios' lo que los proyectos de cultura libre ponen en juego son 'ecologías de prácticas', en el sentido dado por Isabelle Stengers a este término (Stengers 2005).

Por ejemplo, no existe propiamente un umbral que separe lo "público" de lo "privado" en la cultura libre. Las acciones se conciben como "abiertas" y, en este sentido, ciertamente, "públicas": son eventos abiertos a todo el mundo, que frecuentemente disfrutan de una amplia difusión. No obstante, salvo las acciones que se llevan a cabo en plazas o solares abiertos, las reuniones y encuentros de los colectivos de arquitectura y agentes culturales se producen en ámbitos recogidos, muy a menudo en instituciones públicas (como Medialab-Prado o Intermediae), a veces en los estudios, talleres o locales de los propios colectivos o asociaciones. Sin embargo, a pesar del carácter aparentemente "privado" que podría achacársele a este tipo de reuniones, no es infrecuente que algunas personas relaten éstas en vivo, en Twitter o Facebook. No quiero con ello ni mucho menos insinuar que tal práctica dote de suficiente "publicidad" a las reuniones. Lo que quiero hacer notar es que la distinción público-privado no es un operador que guíe sus prácticas. Lo que éstas ponen en juego, más bien, son imágenes, relatos y herramientas que arriesgan otra espacialidad y otra afectividad, y en cualquier caso un relato sobre ciudad que desde luego no encuentra acomodo en el binomio clásico público-privado.

Tres de estas prácticas son la documentación, el archivo y el relato. Los encuentros, las discusiones, las reflexiones, los acuerdos, los desacuerdos, se documentan, muchas veces a varias manos, en documentos compartidos en la nube, cuya redacción avanza a ráfagas esporádicas. Los archivos que alojan estos documentos son, casi siempre, públicos y abiertos, y nutren, a su vez, otras ecologías, otros sistemas, otros archivos. Unos y otros se citan, se referencian, se enlazan, se tuitean, se miran, a veces se leen deprisa y corriendo, a veces se leen en profundidad.

Los encuentros y las discusiones desembocan también en la redacción de relatos, de reflexiones, firmados en ocasiones de forma colectiva, en ocasiones a título individual. Ello da pie a cierta confusión de identidades y de voces, que despliega una percepción de multiplicidad proliferativa. Así más que una pluralidad de voces y de sujetos (ahora individuos, ahora colectivos) lo que pareciera abrirse es un espacio postplural donde la distinción entre 'una' o 'muchas' voces apenas tiene sentido, pues lo que se pone en juego es la capacidad de bifurcación, de 'análisis', en su sentido 
etimológico de 'escisión' o 'desacoplamiento', que los relatos proponen. Los relatos se copian, se editan, se transforman; se citan, se enlazan, se expanden y se contraen. Desacopladas, las partes no aspiran a reintegrarse en un nuevo y abarcador relato. Su desacoplamiento, a veces, tiene un efecto liberador, e impulsa nuevas bifurcaciones, nuevos desacoplamientos; otras veces, simplemente, las frases, los tuits, los enlaces, caen en el olvido y desaparecen.

Por supuesto estas ecologías son mediáticas, en el sentido de que se despliegan a través de diversos medios. Pero no creo que convenga pensarlas desde, o reducirlas a, una expresión más de nuestra cultura digital, pues si algo las caracteriza es su imbricación en proyectos específicos de liberación material de la ciudad.

No hay asambleas, por tanto, y tampoco hay propiamente relaciones (en el sentido antropológico del término, es decir, relaciones sociales que se auto-explicitan como relaciones analíticas). Hay redes, sin duda, si bien el concepto de red está cargado de una potencia tecno-política que, en el caso que nos ocupa, no es un elemento saliente o significador. No hay una búsqueda de la organización 'red' como forma política (salvo en ocasiones muy puntuales y concretas).

No hace mucho propuse la figura del 'prototipo' para pensar la antropología de la cultura libre. El prototipo se caracteriza por esquivar las categorías pluralistas de la modernidad. Por ejemplo: el código fuente del software libre permanece siempre 'abierto' a nuevas contribuciones, ediciones, modificaciones, etc. No existe propiamente 'una' fuente última del código, como tampoco se puede hablar estrictamente de 'muchas'

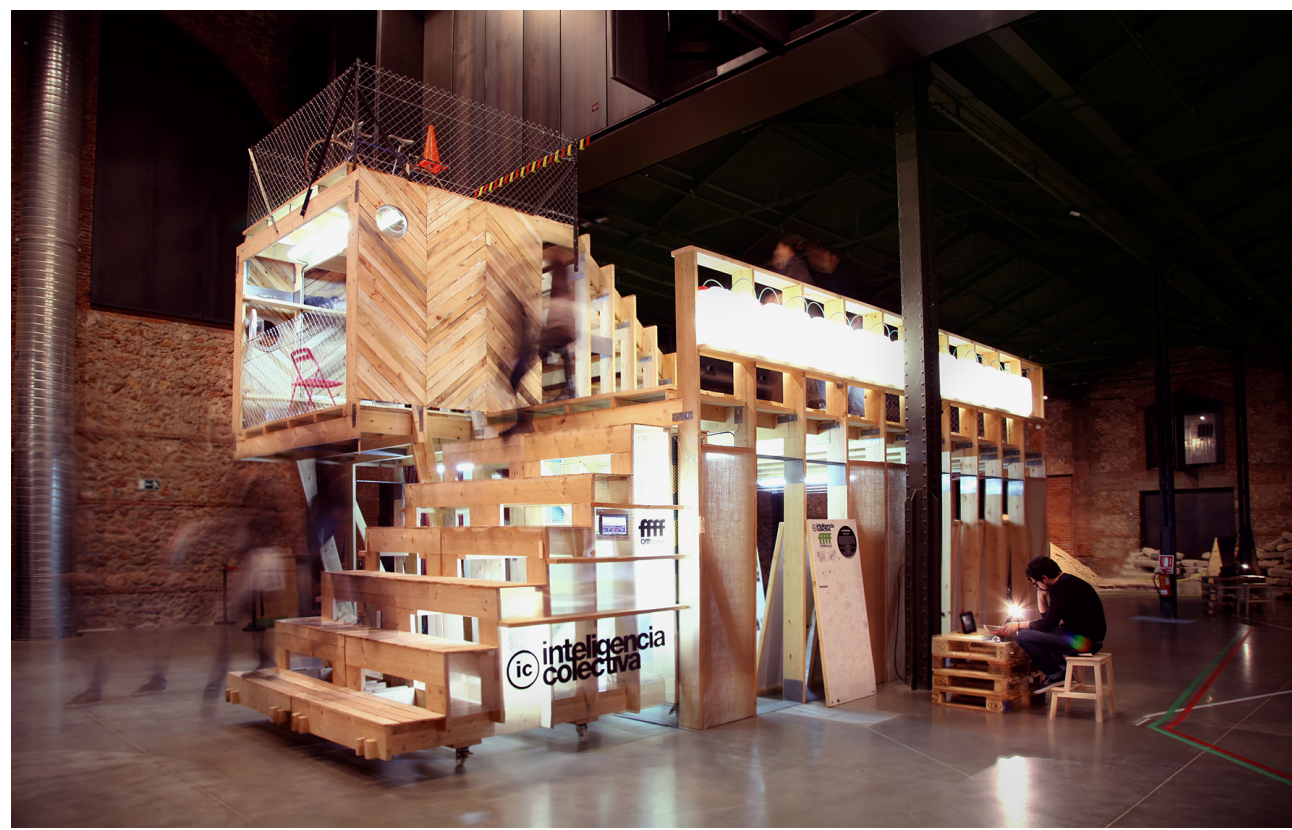

Oficina de Inteligencias Colectivas, Matadero, Madrid, 2012. Autor: Inteligencias Colectivas. La oficina se concibe como un prototipo de prototipos: un sistema constructivo diseñado a partir de soluciones constructivas informales y tecnologías artesanales encontradas a pie de calle en ciudades de medio mundo. 
fuentes. En su apertura infinitiva el código nunca llega a cerrarse, nunca llega a ser 'uno', al tiempo que mantiene viva la posibilidad de que se den más de los 'muchos' proyectos que ya existen. El prototipo, por tanto, es 'menos que uno y más que muchos' (Corsín Jiménez 2014). Decimos del prototipo entonces que es un operador que permite pensar desde otra lógica que la de la pluralidad (uno/muchos) y la diferencia (uno/otro). Más aún: el prototipo nos invita a pensar formas de complejidad distintas a los modelos que las ciencias sociales hemos importado desde las ciencias biológicas (por ejemplo la auto-organización) o las ciencias físico-químicas (por ejemplo la emergencia sistémica). A diferencia de éstos la complejidad del prototipo se caracteriza por la 'apertura' como operador recursivo radical.

Todo esto suena muy confuso, lo sé. Así que voy a ensayar otro registro.

Mi propuesta, en realidad, es muy sencilla: quiero sugerir que lo social, hoy, resulta muy difícil de aprehender, muy difícil de 'ver'. Vemos efectos de lo social por todas partes pero nos cuesta encontrar un concepto que permita pausarlo, asentarlo, apoyarnos en él. No ayudan, desde luego, la precariedad y la fragilidad que acechan al mundo cultural en general, y a la cultura libre en particular, por definición efímera y a la fuga, siempre en pleno vuelo. Todos los conceptos nos parecen insuficientes, siempre dejan algo fuera. Echarle mano a un concepto como el de 'relación', que ha dado juego al pensamiento sociológico durante más de trescientos años, nos resulta hoy impensable.

Quisiera proponer, entonces, que esta dificultad de ver y aprehender lo social sea un momento constitucional de su devenir: apenas lo vemos porque está difuminado, porque está borroso, porque tan pronto aparece como desparece, se borra. Hay un impulso auto-borrador en lo social.

Volvamos a la cultura libre. Las proyectos de cultura libre se organizan en torno a lo que comúnmente se denominan estados 'borrador', proyectos 'en beta': documentos o diseños compartidos, en elaboración permanente, con temporalidades impredecibles, desatadas; licencias abiertas, que permiten la copia, reproducción, edición y distribución de la obra original; espacios de la ciudad que mudan, que se camuflan, que se amueblan y desamueblan; materiales reciclados; listas de correos que recogen y continúan hilos de discusiones en Facebook que recogen y continúan mensajes de Whatsapp que recogen y continúan conversaciones mantenidas durante las cañas tras una jornada de trabajo en un solar urbano.

En este sentido la forma borrador no designa tanto dispositivos o infraestructuras inacabadas como herramientas abiertas; dinámicas no tanto inclusivas como explosivas, que responden a emergencias y urgencias de temporalidades erráticas y concentradas; ecosistemas no tanto emergentes como biomiméticos, frágiles telas de araña que sostienen mundos complejos. Esta fragilidad marca de este modo, también, sus lindes, sus umbrales, haciéndolos borrosos, porosos, mudables, a veces incluso invisibles. Las personas entran y salen, solapándose y confundiéndose las identidades, los roles, las capacidades y los trabajos: ahora colectivos trabajando para una institución pública en un solar, ahora solares trabajando para un colectivo en una institución pública; hoy bajo la denominación y el recurso de la infraestructura, mañana tras el código y el algoritmo del archivo, pasado mañana con la identidad de la asociación cultural. Subvenciones, premios, becas, encomiendas, contratos, ayudas a la investigación; firmando como artistas, como cooperantes, como investigadores, como arquitectos, como mediadores culturales. 
En este 'auto-borrarse' en que incurren personas, identidades, fronteras y materialidades, podríamos quizás encontrar una imagen para esa forma de relacionalidad que se da en las colaboraciones experimentales. 'Colaboración' y 'experimentación': ahí encontramos sus momentos empírico y conceptual, respectivamente. Dicho en términos del XVII: su 'asamblea' y sus 'matters of fact'. ¿Pero qué hay de la 'relación’? ¿Cuál sería el operador dúplex que haría las veces hoy de la 'relación'?

Quizás el nuestro no sea tanto un operador duplicativo (un dúplex) como uno divisivo. Quizás por eso nos cuesta tanto 'ver' y nombrar lo social, pues cada vez que miramos ya no está, se resta y sustrae de sí mismo, como un gesto que a medida que avanza se auto-borra.

\section{BIBLIOGRAFÍA CITADA}

Corsín Jiménez, Alberto. 2014. "Introduction. The Prototype: More than Many and Less than One". Journal of Cultural Economy 7(4): 381-98. doi:10.1080/17530350.2013.858059.

Corsín Jiménez, Alberto y Adolfo Estalella. 2016. «Ecologies in Beta: The City as Infrastructure of Apprenticeships", en Penny Harvey, Casper Bruun Jensen y Atsuro Morita (eds.), Infrastructures and Social Complexity: s/n. Londres y New York: Routledge.

Corsín Jiménez, Alberto, Adolfo Estalella y Zoohaus Collective. 2014. «The Interior Design of [Free] Knowledge". Journal of Cultural Economy 7(4): 493-515. doi:10.1080/17530350.2013.859632.

Harvey, David. 2012. Rebel Cities: From the Right to the City to the Urban Revolution. Londres; Nueva York: Verso Books.

Sánchez-Pinilla, Mario Domínguez, Miguel Ángel Martínez López y Elisabeth Lorenzi Fernández. 2011. Okupaciones en movimiento: derivas, estrategias y prácticas. Madrid: Tierradenadie.

Shapin, Steven. 1988. "The House of Experiment in Seventeenth-Century England». Isis 79(3): 373-404.

Shapin, Steven y Simon Schaffer. 1985. Leviathan and the Air-Pump: Hobbes, Boyle and the Experimental Life. Princeton, NJ: Princeton University Press.

Stengers, Isabelle. 2005. "Introductory Notes on an Ecology of Practices". Cultural Studies Review 11(1): 183-196. doi:10.5130/csr.v11i1.3459.

Strathern, Marilyn. 2014. "Reading Relations Backwards". Journal of the Royal Anthropological Institute 20(1): 3-19. doi:10.1111/1467-9655.12076. 